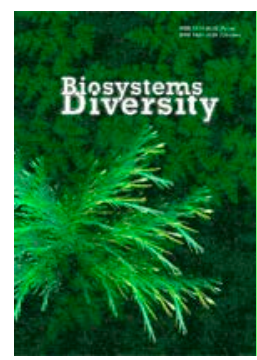

\title{
Long-term dynamics of the state of the fouling community in the Odessa Bay (Black Sea)
}

\author{
A. Y. Varigin \\ Institute of Marine Biology of NASU, Odessa, Ukraine
}

Article info

Received 05.04.2017

Received in revised form 27.04.2017

Accepted 30.04.2017

Institute of Marine Biology of NASU, Pushkinskay Str., 37,

Odessa, 65011, Ukraine.

Tel.:+38-048-725-09-18.

E-mail: sealife_1@mail.ru

\begin{abstract}
Varigin, A. Y. (2017). Long-term dynamics of the state of the fouling community in the Odessa Bay (Black Sea). Biosystems Diversity, 25(2), 61-66. doi:10.15421/011709

This article examines the long-term dynamics of the qualitative and quantitative characteristics of the coastal fouling community of Odessa Bay (Black Sea) for the last 40 years. It compares the data on this community, obtained by different researchers in 1976, 1994 and 2016 was conducted. The number of species included in the fouling community decreased from 103 (1976) to 43 (1994) and then reached to 62 in 2016. As a possible reason for this reduction in the species composition of the community the influence of large-scale anthropogenic eutrophication, which was already strongly evident in the north-western part of the Black Sea in the 1970s, is proposed. This phenomenon was accompanied by periodic outbreaks of mass abundance of planktonic algae, secondary water pollution, the development of hypoxia and a frequent suffocation effect on the benthos, which caused the disappearance from the community of 41 species of invertebrates. The reduction in the number of species affected representatives of the following taxons: Polychaeta, Amphipoda, Gastropoda and Bivalvia. Currently, the core of the community includes the same species of invertebrates, as in the past. It is based on Bivalvia mussels Mytilus galloprovincialis. Among the attached forms Mytilaster lineatus (Bivalvia) and Amphibalanus improvisus (Cirripedia) play a leading role, and among mobile - representatives of Polychaeta, Isopoda, Amphipoda and Gastropoda. It is shown that 10 of the 25 species, recorded the first time for this community in the 1970s, have become abundant in modern conditions. The primacy in the relative density in the composition of the community at the present time has passed from the amphipod crustaceans to bivalve molluscs. The highest relative biomass, both in the past and in the present-day conditions was observed in representatives of Bivalvia. The structure of the resistance of the fouling community to the effects of unstable environmental factors specific to the coastal zone is discussed. Overall, it was found that those species which have been preserved in the community are habitat generalist invertebrates, which are well adapted to the sharp fluctuations in temperature and salinity of sea water, as well as to periodic storm impact.
\end{abstract}

Keywords: fouling community; species composition; the long-term dynamics; Odessa Bay; Black Sea

\section{Долговременная динамика состояния сообщества обрастания Одесского залива Черного моря}

\author{
А. Ю. Варигин
}

Институт морской биологии НАНУ, Одесса, Украина

Проведен анализ долговременных изменений качественного состава и количественных параметров прибрежного сообщества обрастания Одесского залива Черного моря за последние 40 лет. Зафиксировано сокращение более чем в полтора раза общего количества видов, входящих в состав сообщества. Показано, что 10 из 25 видов, впервые отмеченных для данного сообщества в 1970-х годах, в современных условиях стали массовыми. Выявлена тенденция сохранения в составе сообщества эврибионтных видов беспозвоночных, хорошо приспособленных к обитанию в условиях нестабильности факторов внешней среды, характерных для береговой зоны моря. Показано, что двустворчатые моллюски Mytilus galloprovincialis в настоящее время, как и 40 лет назад, продолжают составлять основу сообщества обрастания. Роль субдоминантного вида в последнее время перешла к более мелкому и стрессоустойчивому моллюску Mytilaster lineatus. Характерными видами сообщества, встречаемость которых превышает $50 \%$, на протяжении всех изученных лет остаются одни и те же беспозвоночные. В настоящее время в этот список попали Nereis zonata и Platynereis dumerilii (Polychaeta), Microdeutopus gryllotalpa и Melita palmata (Amphipoda), Pusillina lineolata (Gastropoda), а покинули его Jassa ocia и Ericthonius difformis (Amphipoda), причем последний вид вообще исчез из состава сообщества. Всего за последнее время систематический состав сообщества стал беднее на 41 вид беспозвоночных. В современных условиях в сообществе обрастания Одесского залива Черного моря как по численности, так и по биомассе доминируют двустворчатые моллюски.

Ключевые слова: сообщество обрастания; видовой состав; долговременная динамика; Одесский залив; Черное море

\section{Введение}

$\mathrm{B}$ середине $\mathrm{XX}$ века в связи с угрозой оползней у берегов Одесского залива проведены масштабные берегоукрепитель- ные работы. Инженерный комплекс по защите берегов Одессы от разрушения состоял из разветвленной дренажной системы, расположенной на приморских склонах и бетонных гидротехнических сооружениях в виде траверсов и волноломов, установ- 
ленных в море вдоль береговой линии. Такое крупномасштабное строительство, сопровождающееся намывкой песка на пляжи, оказало существенное влияние на состояние прибрежных морских сообществ (Zaitsev and Jacenko, 1983). В наибольшей степени это проявилось в отношении биоценоза скал и камней, так как естественные твердые субстраты в прибрежной зоне были засыпаны вновь намытым песком. С другой стороны у берегов Одессы появились искусственные твердые субстраты в виде гидротехнических сооружений, общая площадь подводной поверхности которых многократно превышала таковую у ранее расположенных здесь скал и камней.

Спустя некоторое время после окончания строительства на подводной поверхности новых траверсов и волноломов сформировалось сообщество обрастания. Основу его составили прикрепленные организмы, распространение которых происходит с помощью планктонных личинок (Brajko and Dolgopolskaja, 1974; Grintsov and Poltarukha, 2004). Подобные сообщества развиваются на искусственных субстратах и в других морях, например, в Средиземном (Sara et al., 2007; Pierri et al., 2010). Со временем сообщество обрастания гидротехнических сооружений Одесского залива стало не только своеобразным биофильтром для окружающих морских вод благодаря фильтрационной активности мидий, но и мощным источником ларватона для пелагиали (Govorin et al., 2004; Govorin and Shatsillo, 2010; Vorobyova and Sinegub, 2000). Состояние этого вновь образовавшегося сообщества впервые изучено в 1970-е годы (Kaminskaja et al., 1977). Затем в 1990-е годы проведено аналогичное исследование (Alexandrov and Khodakov, 1999).

Цель данной статьи - определить многолетнюю динамику видового состава и количественного развития сообщества обрастания Одесского залива с помощью сравнения данных предыдущих исследователей с современными показателями состояния этого сообщества.

\section{Материал и методы исследований}

Материалом послужили пробы, отобранные в 2016 г. на подводной поверхности берегозащитных сооружений, а также скал и камней, расположенных вдоль береговой линии Одесского залива от мыса Большой Фонтан (46²2,482' с. ш., $30^{\circ} 44,713$ ' в. д.) до мыса Северный (46³3,381’ с. ш., $30^{\circ} 48,652^{\prime}$ в. д.). Всего собрано 32 пробы. При этом использовали металлическую рамку размером $20 \times 20 \mathrm{~cm}$, обтянутую мельничным газом. Содержимое каждой рамки промывали через систему почвенных сит с минимальным размером ячеи 0,5 мм. Собранных беспозвоночных идентифицировали до вида, подсчитывали и взвешивали. Современные данные сравнивали с материалами других исследователей для этих же районов моря 1976 (Kaminskaja et al., 1977) и 1994 годов (Alexandrov and Khodakov, 1999). Сравнение видового состава сообщества разных лет проводили с помощью индекса сходства Чекановского - Серенсена (Pesenko, 1982). При описании динамики видов, входящих в сообщество, использовали общепринятые показатели: численность, биомасса, индекс плотности и встречаемость (Kaminskaja et al., 1977).

\section{Результаты и их обсуждение}

Сравнение материалов по видовому составу изучаемого сообщества за 2016 год с данными, полученными в том же районе моря другими исследователями в 1976 и 1994 гг., свидетельствует о существенном изменении соотношения отдельных видов беспозвоночных, произошедшем за последние 40 лет. Число видов, входящих в состав сообщества обрастания, сократилось со 103 в 1976 г. (Kaminskaja et al., 1977) до 43 в 1994 г. (Alexandrov and Khodakov, 1999) и затем к 2016 году достигло 62. При этом наименьший коэффициент общности видов отмечен при сравнении состава сообщества в 1976 и 1994 гг., наибольший - при сопоставлении данных 1976 и 2016 годов. Максимальное число общих видов также зафик- сировано в составе сообщества обрастания в 70-х годах XX и в начале XXI столетия (табл. 1).

\section{Таблица 1}

Число общих видов и коэффициент общности

Чекановского - Серенсена в сообществе обрастания Одесского залива Черного моря в различные периоды

\begin{tabular}{ccc}
\hline $\begin{array}{c}\text { Сравниваемые } \\
\text { периоды }\end{array}$ & $\begin{array}{c}\text { Число } \\
\text { общих видов }\end{array}$ & $\begin{array}{c}\text { Коэффициент } \\
\text { общности }\end{array}$ \\
\hline $1976-1994$ & 35 & 0,49 \\
$1994-2016$ & 29 & 0,58 \\
$1976-2016$ & 50 & 0,61 \\
\hline
\end{tabular}

Систематический состав сообщества обрастания изменился за исследуемый период в основном за счет исчезновения ранее обитавших здесь видов. В 1970-е годы в Одесском заливе наблюдалось сокращение числа видов губок с 9 до 2. При этом колонии Haliclona implexa (Schmidt, 1868) и Suberites prototypus Czerniavsky, 1880 обнаружены лишь на некотором расстоянии от берега на глубине 2-3 м (Kaminskaja et al., 1977). В материалах 2016 года губки не обнаружены. В то же время колонии гидроидных полипов Obelia longissima (Pallas, 1766), актинии Diadumene lineata (Verrill, 1869), мшанки Einhornia crustulenta (Pallas, 1766), асцидии одиночные Molgula euprocta (Drasche, 1884) и колониальные Botryllus schlosseri (Pallas, 1766), ранее не обнаруженные в обрастании, в 2016 г. отмечены в районах моря, наименее подверженных волновому воздействию. Личинки хирономид Halocladius vitripennis (Meigen, 1818), Thalassomyia frauenfeldi Schiner, 1856 и Clunio marinus Haliday, 1855 присутствовали в сообществе обрастания во все периоды исследования, за исключением последнего вида, который не отмечен в материалах 1994 года.

Число видов многощетинковых червей, обитавших в сообществе обрастания за период с конца 1970-х до начала 1990-х годов, сократилось в пять раз. Из 20 видов полихет, отмеченных здесь ранее, в 1994 году обнаружены лишь четыре: Exogone naidina Örsted, 1845, Alitta succinea (Leuckart, 1847), Hediste diversicolor (O. F. Müller, 1776) и Polydora cornuta Bosc, 1802 (Aleksandrov, 2008). Ранее обычный в обрастании представитель трубчатых многощетинковых червей Spirorbis pusilla Rathke, 1837 к этому времени уже не встречался в Одесском заливе (Alexandrov and Khodakov, 1999). Аналогичное явление отмечено для этого вида, обитавшего ранее у берегов Крыма (Brajko, 1985).

К 2016 году число видов полихет, входящих в состав сообщества обрастания Одесского залива, по сравнению с данными 1990-х годов, увеличилось в три раза, так и не достигнув уровня 1970-х годов (рис.). При этом как в 1976, так и в 2016 году здесь зафиксировано 10 общих видов: Genetyllis tuberculata (Bobretzky, 1868), Mysta picta (Quatrefages, 1866), Harmothoe imbricata (Linnaeus, 1767), Salvatoria clavata (Claparède, 1863), A. succinea, H. diversicolor, Nereis zonata Malmgren, 1867, Platynereis dumerilii (Audouin et M.-Ed., 1834), P. cornuta, Fabricia stellaris (Müller, 1774).

Представители усоногих раков Amphibalanus improvisus (Darwin, 1854) обнаружены в сообществе обрастания во все периоды исследований. Среди десятиногих ракообразных наиболее резкое сокращение числа видов произошло в период с конца 1970-х по начало 1990-х годов. К 1994 году из 9 видов Decapoda, обитавших здесь ранее, осталось только 2: Palaemon adspersus Rathke, 1837 и Rhithropanopeus harrisii (Gould, 1841) (Aleksandrov, 2008).

В этот период в северо-западной части Черного моря наблюдалась крупномасштабная антропогенная эвтрофикация вод (Losovskaja et al., 1990; Alexandrov and Zaitsev, 1998). Концентрации компонентов взвешенного органического вещества в морской воде достигли аномально высоких значений (Kukushkin, 2013). Эти процессы сопровождались периодическими массовыми вспышки численности планктонных водорослей, вторичным загрязнением вод, развитием гипоксии и частыми 
заморами бентоса (Losovskaja, 1988; Zaitsev, 1992). Последствия этого явления негативно повлияли на развитие бентосных организмов (Zaitsev and Mamaev, 1997; Vorobyova et al., 2003).

Среди представителей фитобентоса доминирующая роль перешла от крупных многолетних видов макрофитов к мелким короткоцикличным и тонкоразветвленным формам (Minicheva, 1996). Так, в 1960-х годах доминирующим видом в прибрежной зоне Одесского залива была крупная многолетняя бурая водоросль Cystoseira barbata (Good. et Wood) Agardh, биомасса которой достигала 5920 г/м². Но уже к концу 1970-х годов ее встречаемость снизилась вдвое, а биомасса уменьшилась на порядок (Eremenko, 1977). Затем этот макрофит полностью исчез из состава фитобентоса Одесского залива, а его место занял комплекс более мелких короткоживущих видов водорослей (Minicheva et al., 2013).

В настоящее время фитокомпоненты сообщества обрастания Одесского залива в основном формируются такими видами из отдела Chlorophyta как Cladophora laetivirens (Dillwyn) Kutz, 1843, Bryopsis plumosa (Huds.) C. Agardh, 1823 и Ulva intestinalis L., 1753. Среди красных водорослей, часто прикрепляющихся к раковинам мидий, наиболее распространены Ceramium rubrum Auct. Rrauss, 1846, Callithamnion corymbosum (Sm.) Lyngb., 1819 и Lomentaria clavellosa (Turn.) Gail., 1863. Бурые водоросли представлены видами, значительно уступающими по размерам обитавшей здесь ранее Cystoseira barbata. Среди них наиболее массовыми являются Ectocarpus siliculosus (Dillwyn) Lyngb., 1819 и Scytosiphon lomentaria (Lyngb.) Link., 1833. В условиях прибрежного сообще- ства обрастания талломы этих макрофитов часто покрываются эпифитными микроводорослями, ведущая роль среди которых принадлежит представителям диатомовых.

В период наблюдавшейся эвтрофикации вод северо-западной части Черного моря существенные изменения произошли также в составе зообентоса. В первую очередь от последствий этого явления пострадали некоторые виды десятиногих ракообразных, планктонные личинки которых наиболее чувствительны к эвтрофикации и загрязнению морской среды (Makarov, 2004). Резкое сокращение их численности послужило основанием для включения таких видов как Carcinus aestuarii Nardo, 1847, Liocarcinus navigator (Herbst, 1794), Pilumnus hirtellus (Linnaeus, 1761) и Xanto poressa (Olivi, 1792) в список Красной книги Черного моря (Black Sea Red Data Book, 1999).

K началу XXI века произошло постепенное изменение качества вод северо-западной части Черного моря. В стоке крупных рек, впадающих в эту часть моря, отмечено уменьшение содержания минеральных форм азота, фосфора и кремния (Berlinskij et al., 2001). Снижение уровня эвтрофикации морских вод привело к частичному восстановлению видового разнообразия северо-западной части Черного моря, включая акваторию Одесского залива (Makarov and Varigin, 2007). К 2016 году количество видов десятиногих в составе сообщества обрастания снова достигло 9, хотя в этом списке вместо рака-отшельника Diogenes pugilator (Roux, 1829) появился крабоид Pisidia longimana (Risso, 1816). (рис.).

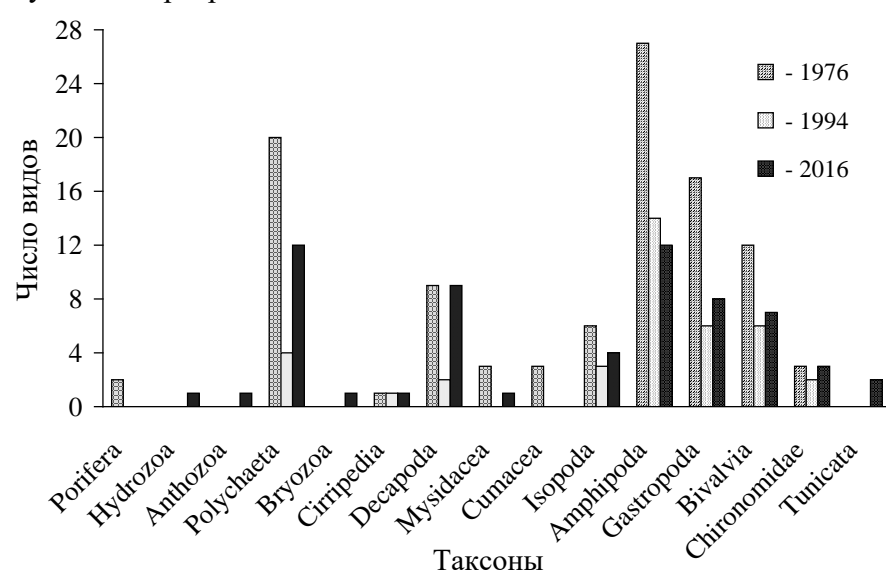

Рис. Число видов каждого таксона в сообществе обрастания в 1976 г. по данным Kaminskaja et al. (1977), в 1994 по данным Aleksandrov (2008) и в 2016 г. по собственным данным

Из трех видов мизид, отмеченных в 1976 г., в 2016 г. обнаружен только один - Siriella jaltensis Czerniavsky, 1868. Из 6 видов равноногих ракообразных, отмеченных в 1976 г., в 1994 г. обнаружены 3, а в 2016 - 4 (рис.). При этом два вида (Lekanesphaera monodi (Arcangeli, 1934) и Idotea balthica basteri (Pallas, 1772)) обитали в сообществе во все периоды исследований. Число видов разноногих ракообразных за исследуемый период сократилось почти вдвое (рис.). Из 27 видов отряда Amphipoda, зафиксированных в сообществе обрастания в 1976 г., в 1994 г. осталось только 14, а в 2016 г. - 12. При этом 7 видов (Stenothoe monoculoides (Montagu, 1815), Echinogammarus olivii (Milne-Edwards, 1830), Melita palmata (Montagu, 1804), Dexamine spinosa (Montagu, 1813), Microdeutopus gryllotalpa Costa, 1853, Ampithoe ramondi Audouin, 1826 и Crassicorophium bonellii (Milne-Edwards, 1830)) обнаружены во все сравниваемые периоды.

Число видов брюхоногих моллюсков, обитающих в сообществе обрастания, за последние 40 лет сократилось более чем вдвое. Из 17 видов Gastropoda, зафиксированных в 1976 г., в 1994 г. обнаружены 6, а в 2016 г. - 8. Из них 4 вида (Rissoa splendida Eichwald, 1830, R. membranacea (J. Adams, 1800), Setia valvatoides (Milaschewitsch, 1909) и Hydrobia acuta (Draparnaud, 1805)) встречались в составе сообщества в течение всех изученных лет. Из 12 видов двустворчатых моллюсков, отме- ченных в 1976 г., в 1994 г. обнаружены 6, а в 2016 г. - 7 (рис.). Несмотря на двукратное уменышение числа видов Bivalvia, два из них (доминирующий вид Mytilus galloprovincialis Lamarck, 1819 и его субдоминант Mytilaster lineatus (Gmelin, 1791)) являются основой сообщества обрастания на протяжении всех изученных лет. Остальные четыре вида (Cerastoderma glaucum (Bruguière, 1789), Abra segmentum (Récluz, 1843), Mya arenaria Linnaeus, 1758 и Lentidium mediterraneum (O. G. Costa, 1830)) встречались в сообществе обрастания лишь на ювенильной стадии развития.

Количественное развитие основных систематических групп сообщества обрастания существенно изменилось за исследуемый период. Численность двустворчатых моллюсков, в основном мидии и митилястера, формирующих основу сообщества на естественных субстратах, за последние 40 лет увеличилась почти в 40 раз, а биомасса - более чем на два порядка (табл. 2). На искусственных субстратах, в частности на подводной поверхности берегоукрепительных сооружений эти изменения были не столь значительны: как численность, так и биомасса увеличилась в 1,5-2,0 раза.

В процентном отношении численность Bivalvia увеличилась лишь в 5 раз, а биомасса - в 1,3 раза (табл. 2). Это свидетельствует о том, что двустворчатые моллюски по-прежнему составляют основу сообщества обрастания. Причем если рань- 
ше наибольшую численность в процентном отношении (58\%) формировали 27 видов разноногих ракообразных, то в последнее время это первенство (77\%) перешло к двустворчатым моллюскам, в частности, к митилястеру. Этот сравнительно небольшой по размеру моллюск отличается высокой плодовитостью, а степень его устойчивости к воздействию неблагоприятных факторов среды выше, чем у мидий. Так, летом 2010 года в Одесском заливе в течение продолжительного времени наблюдалась аномально высокая температура воды. В результате сочетания этого и некоторых других сопутствующих неблагоприятных факторов большинство особей мидий погибли, в то время как митилястер, входящий в состав сообщества обрастания, не только выжил, но и затем резко увеличил свои количественные параметры (Govorin and Shatsillo, 2012). Благодаря этой устойчивости в последние годы митилястер стал руководящим видом сообщества обрастания, расположенного у берегов Крыма, вытеснив прежнего доминанта мидию (Kovaleva et al., 2012; Kovaleva et al., 2014).

\section{Таблица 2}

Численность (N) и биомасса (B) основных систематических групп сообщества обрастания Одесского залива Черного моря в 1976* и 2016 гг.

\begin{tabular}{|c|c|c|c|c|c|c|c|c|}
\hline \multirow{2}{*}{ Таксоны } & \multicolumn{2}{|c|}{$\mathrm{N}$, эКЗ. $\cdot \mathrm{M}^{-2}$} & \multicolumn{2}{|c|}{$\mathrm{N}, \%$} & \multicolumn{2}{|c|}{$\mathrm{B}, \Gamma^{\cdot} \cdot \mathrm{M}^{-2}$} & \multicolumn{2}{|c|}{$\mathrm{B}, \%$} \\
\hline & 1976 & 2016 & 1976 & 2016 & 1976 & 2016 & 1976 & 2016 \\
\hline Polychaeta & 165 & 3077 & 2,38 & 5,67 & 0,15 & 16,08 & 0,26 & 0,25 \\
\hline Isopoda & 410 & 1927 & 5,91 & 3,55 & 2,95 & 27,56 & 5,14 & 0,43 \\
\hline Amphipoda & 3997 & 7164 & 57,59 & 13,20 & 11,14 & 24,09 & 19,42 & 0,38 \\
\hline Gastropoda & 1302 & 444 & 18,76 & 0,82 & 1,01 & 0,85 & 1,76 & 0,01 \\
\hline Bivalvia & 1066 & 41665 & 15,36 & 76,76 & 42,12 & 6352,35 & 73,42 & 98,93 \\
\hline
\end{tabular}

Примечание: * - по данным Kaminskaja et al. (1977).

Численность M. lineatus, активно развивающегося в пределах сообщества обрастания Одесского залива, иногда достигает 35 тыс. экз./м². При этом более $80 \%$ общего числа моллюсков приходится на молодь размером 1-3 мм. Ведущая роль в формировании биомассы сообщества в процентном отношении как ранее, так и сейчас принадлежит двустворчатым моллюскам. Причем происходит это в основном за счет активного роста и развития мидии, которая продолжает оставаться руководящим видом сообщества обрастания Одесского залива (табл. 2).

Несмотря на то, что за сорокалетний период в сообществе обрастания число видов разноногих ракообразных сократилось более чем вдвое, их вклад в общую численность сообщества остается значительным (13,2\%) по сравнению с другими систематическими группами, исключая двустворчатых моллюсков. В то же время доля этих беспозвоночных в общей биомассе сообщества уменьшилась на порядок. Численность равноногих ракообразных в процентном отношении за это время изменилась незначительно, а биомасса уменьшилась более чем в 10 раз (табл. 2). Доля многощетинковых червей в общей численности сообщества увеличилась более чем в два раза, а в общей биомассе - почти не изменилась. Численность брюхоногих моллюсков в процентном отношении уменьшилась с 1976 по 2016 г. более чем в 20 раз, а биомасса - более чем на порядок (табл. 2).

Сопоставление данных по встречаемости и количественным параметрам представителей сообщества обрастания Одесского залива в разные периоды исследований показало, что характерными видами (встречаемость выше 50\%) на протяжении 40 лет остаются одни и те же беспозвоночные. Исключение составили лишь некоторые виды, одни из которых исчезли из состава сообщества, а другие - наоборот, получили в последнее время массовое развитие (табл. 3). К доминирующей во все изученные годы мидии, составляющей основу сообщества, присоединился субдоминант митилястер, который в 1976 г. не указывался среди характерных видов (Kaminskaja et al., 1977), хотя в 1994-м уже был таковым (Alexandrov and Khodakov, 1999).

Проведенный анализ показал, что организмы, составляющие ядро сообщества обрастания Одесского залива, являются эврибионтными видами, приспособленными к жизни в широком диапазоне изменчивости абиотических факторов среды. Это явление характерно для большинства прибрежных сообществ. В береговой зоне моря нередко происходит активная смена водных масс, сопровождающаяся изменением как температуры, так и солености воды. Так, температура воды в прибрежной зоне Одесского залива в зависимости от сезона года и ветровой обстановки может колебаться в диапазоне от 0,3 до $30{ }^{\circ} \mathrm{C}$, а соленость - от $6,3 \%$ до $17,0 \%$ вследствие изменения стока крупных рек, впадающих в северо-западную часть Черного моря (Docenko, 2002).
Кроме того, прибрежное сообщество обрастания время от времени подвергается штормовому воздействию, особенно в осенне-зимний период. Как показали специальные исследования, структура сообщества проявляет определенную устойчивость в такие периоды повышенной гидродинамической активности водных масс. Последствия шторма проявляются в виде временного снижения численности организмов сообщества, однако соотношение основных таксонов беспозвоночных практически не изменяется. Это свидетельствует о том, что сообщество обрастания представляет собой надвидовую систему, обладающую способностью сохранения постоянства соотношения таксонов в условиях регулярно происходящих внешних воздействий (Polonskij and Grintsov, 2013).

Изучение динамики количественных параметров характерных видов сообщества за последние 40 лет оказалось возможным лишь на основе сравнения их индексов плотности, рассчитанных по данным 1970-х годов (Kaminskaja et al., 1977) и современным показателям (табл. 3). За этот период при $100 \%$ встречаемости индекс плотности мидии увеличился втрое. Для усоногого рака A. improvisus этот показатель увеличился более чем в 20 раз. Количественные параметры мелкого брюхоногого моллюска $S$. valvatoides наоборот уменьшились более чем в 20 раз. В то же время среди характерных видов Gastropoda в сообществе обрастания в 2016 г. отмечена Pusillina lineolata (Michaud, 1830), встречаемость которой ранее была менее 50\%.

Два представителя разноногих ракообразных M. gryllotalpa и M. palmata вошли к 2016 г. в группу характерных видов. В то же время Jassa ocia (Bate, 1862) покинула ee, a Ericthonius difformis Milne-Edwards, 1830 вообще исчез из состава сообщества. Самый мелкий представитель амфипод $S$. топоculoides стал встречаться повсеместно и увеличил свои количественные параметры более чем вчетверо. При этом индекс плотности другого характерного вида разноногих раков A. ramondi уменьшился в три раза, а встречаемость осталась на том же уровне. Остальные амфиподы, входящие в эту группу, за прошедший период изменили свои характеристики незначительно (табл. 3).

Два вида равноногих ракообразных L. monodi и I. balthica basteri, по-прежнему оставаясь характерными видами сообщества со 100\% встречаемостью, к 2016 г. увеличили свои количественные параметры в 2,8 и 11,0 раз, соответственно. Эти виды изопод не только сохранили, но и упрочили свои позиции в сообществе обрастания Одесского залива благодаря некоторым особенностям поведения, питания и размножения. Оба вида хорошо переносят значительные колебания температуры и солености воды, характерные для прибрежной зоны Черного моря. Ведут активный образ жизни, передвигаясь в пределах сообщества с помощью слаженной работы специифического локомоторного аппарата. В случае возникновения 
неблагоприятных условий в прибрежной зоне эти ракообразные совершают временные миграции в более отдаленные от берега районы моря. Они имеют покровительственную окраску внешних покровов, позволяющую им сливаться с фоном субстрата и быть незаметными для хищников. По способу питания они практически всеядны. Проявляют активную заботу о потомстве, вынашивая молодь в выводковых сумках. Такой широкий спектр адаптивных возможностей позволяет этим двум представителям равноногих ракообразных на протяжении длительного времени оставаться характерными видами сообщества обрастания Одесского залива.

Таблица 3

Индекс плотности и встречаемость характерных видов сообщества обрастания Одесского залива Черного моря в $1976^{*}$ и 2016 гг.

\begin{tabular}{|c|c|c|c|c|}
\hline \multirow{2}{*}{ Виды } & \multicolumn{2}{|c|}{ Индекс плотности } & \multicolumn{2}{|c|}{ Встречаемость, \% } \\
\hline & 1976 & 2016 & 1976 & 2016 \\
\hline \multicolumn{5}{|l|}{ Polychaeta } \\
\hline Nereis zonata Malmgren & - & 30 & - & 100 \\
\hline Platynereis dumerilii (Audouin et M.-Ed.) & - & 108 & - & 100 \\
\hline \multicolumn{5}{|l|}{ Cirripedia } \\
\hline Amphibalanus improvisus (Darwin) & 111 & 2446 & 85 & 85 \\
\hline \multicolumn{5}{|l|}{ Isopoda } \\
\hline Lekanesphaera monodi (Arcangeli) & 15 & 42 & 100 & 100 \\
\hline Idotea balthica basteri (Pallas) & 17 & 188 & 100 & 100 \\
\hline \multicolumn{5}{|l|}{ Amphipoda } \\
\hline Stenothoe monoculoides (Montagu) & 3 & 13 & 70 & 100 \\
\hline Microdeutopus gryllotalpa Costa & - & 22 & - & 100 \\
\hline Melita palmata (Montagu) & - & 18 & - & 100 \\
\hline Ampithoe ramondi Audouin & 38 & 13 & 95 & 95 \\
\hline Echinogammarus olivii (Milne-Edwards) & 185 & 240 & 100 & 100 \\
\hline Jassa ocia (Bate) & 29 & - & 100 & 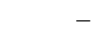 \\
\hline Crassicorophium bonellii (M.- Edwards) & 4 & 5 & 85 & 85 \\
\hline Ericthonius difformis Milne-Edwards & 3 & - & 65 & - \\
\hline \multicolumn{5}{|l|}{ Gastropoda } \\
\hline Setia valvatoides (Milaschewitsch) & 73 & 3 & 85 & 75 \\
\hline Pusillina lineolata (Michaud) & - & 9 & - & 75 \\
\hline \multicolumn{5}{|l|}{ Bivalvia } \\
\hline Mytilus galloprovincialis Lamarck & 2777 & 8407 & 100 & 100 \\
\hline Mytilaster lineatus (Gmelin) & - & 4593 & - & 100 \\
\hline
\end{tabular}

Примечание: * - по данным (Kaminskaja et al., 1977).

В систематической группе многощетинковых червей появились два характерных вида $N$. zonata и $P$. dumerilii, встречаемость которых ранее была меньше $50 \%$ (табл. 3). Эти виды эррантных полихет получили широкое распространение в сообществе обрастания Одесского залива благодаря своим экологическим особенностям. По способу питания они относятся к полифагам. Большую часть их пищевого рациона составляют частицы детрита, микроводоросли и мелкие беспозвоночные (Losovskya, 1977).

Крупные мидии, составляющие основу сообщества обрастания, плотно прикрепляются к субстрату с помощью своих биссусных нитей. При этом образуется сложная трехмерная инфраструктура с множеством укромных убежищ, необходимых для развития более мелких подвижных организмов. Переплетенная сеть биссусных нитей моллюсков представляет собой своеобразную седиментационную ловушку, внутри которой постепенно скапливается питательный детрит. Таким образом, обитающие здесь полихеты и другие мелкие беспозвоночные находят себе пищу и убежище.

Как известно, в материалах исследований 1976 г. описаны 25 видов и один род беспозвоночных в качестве впервые отмеченных для Одесского залива (Kaminskaja et al., 1977). К 2016 году в составе сообщества обрастания из этого списка осталось только 10: по одному виду многощетинковых червей, брюхоногих и двустворчатых моллюсков (P. cornuta, S. valvatoides и C. glaucum), четыре вида разноногих ракообразных (E. olivii, C. bonellii, Hyale pontica Rathke, 1847, Microprotopus longimanus Chevreux, 1887) и три вида личинок хирономид (H. vitripennis, T. frauenfeldi,
C. marinus). Причем три из них (S. valvatoides, E. olivii и C. bonellii) как ранее, так и в настоящее время являются характерными видами сообщества обрастания Одесского залива (табл. 3).

\section{Выводы}

За последние 40 лет состояние сообщества обрастания Одесского залива существенно изменилось. Из состава сообщества исчез 41 вид беспозвоночных. Сокращение числа видов произошло, в основном, за счет представителей таких таксонов как Polychaeta, Amphipoda, Gastropoda и Bivalvia. Однако в ядро сообщества попрежнему входят практически те же организмы. Основу его составляют двустворчатые моллюски. Среди прикрепленных форм ведущую роль играют усоногие раки, а среди подвижных полихеты, изоподы, амфиподы и гастроподы. Превосходство по относительной численности перешло за этот период от разноногих ракообразных к двустворчатым моллюскам, а по относительной биомассе - осталось у последних. Из 25 видов беспозвоночных, описанных ранее в качестве впервые отмеченных для Одесского залива, в настоящее время в составе сообщества обрастания осталось только 10.

\section{References}

Aleksandrov, B. G. (2008). Gidrobiologicheskie osnovy upravlenija sostojaniem pribrezhnyh jekosistem Chernogo morja [Hydrobiological bases of management of the coastal ecosystem of the Black Sea]. Naukova Dumka, Kyiv (in Russian).

Alexandrov, B. G., \& Khodakov, I. V. (1999). Izmenenie struktury i samoochistitel'noj sposobnosti obrastanija pribrezhnoj zony Chernogo morja v uslovija antropogennogo vozdejstvija [Changes in the structure and self-cleaning ability of the fouling of the coastal zone of the Black Sea in terms of human impact]. Ecological Problems of the Black Sea, 1, 192-197 (in Russian).

Alexandrov, B. G., \& Zaitsev, Y. P. (1998). Black Sea biodiversity in eutrophication conditions. Conservation of the biological diversity as prerequisite for sustainable development in the Black Sea region. Kluwer Academic Publishers, Dordrecht.

Berlinskij, N. A., Bogatova, Y. I., \& Garkavaja, G. P. (2001). O razvitii gipoksii v severo-zapadnoj chasti Chernogo morja v sovremennyj period [On the development of hypoxia in the northwestern part of the Black Sea in the modern period]. Scientific Notes of Ternopol State Pedagogical University. Series: Biology, 15, 114-116 (in Russian).

Black Sea Red Data Book (1999). UNOPS, New York.

Brajko, V. D. (1985). Obrastanie v Chernom more [Fouling in the Black Sea]. Naukova Dumka, Kyiv (in Russian).

Brajko, V. D., \& Dolgopolskaja, M. A. (1974). Osnovnye cherty formirovanija cenoza obrastanija [The main features of the formation of fouling cenosis]. Hydrobiological Journal, 10(1), 11-18 (in Russian).

Docenko, S. A. (2002). Sezonnaja izmenchivost' osnovnyh gidrologicheskih parametrov в Odesskom regione severo-zapadnoj chasti Chernogo morja [Seasonal variability of basic hydrological parameters in the Odessa region of the north-western part of the Black Sea]. Ecological safety of coastal and shelf zones and complex use of shelf resources, 6, 47-57 (in Russian).

Eremenko, T. I. (1977). Sukcessii fitobentosa severo-zapadnogo poberezh'ja Chernogo morja [Successions of phytobenthos in the northwest coast of the Black Sea]. Biology of Sea, 43, 45-54 (in Russian).

Govorin, I. A., \& Shatsillo, E. I. (2010). Formation of the filtering potential of the mussel and Mytilaster settlements within anthropogenically transformed coastal zone of the Black Sea. Hydrobiological Journal, 46(2), 3-12.

Govorin, I. A., \& Shatsillo, E. I. (2012). Perifitonnye poselenija midij Mytilus galloprovincialis (Lamarck, 1819) i mitiljastera Mytilaster lineatus (Gmelin, 1791) v uslovijah anomal'no vysokoj temperatury pribrezhnyh morskih vod [The periphyton settlements of mussels Mytilus galloprovincialis (Lamarck, 1819) and mytilasters Mytilaster lineatus (Gmelin, 1791) in abnormal high temperature conditions of the coastal waters]. Ruthenica, 22(2), 101-110 (in Russian).

Govorin, I. A., Adobovsky, V. V., \& Shatsillo, E. I. (2004). Fouling of hydroengineering structures with mussels as a natural biofilter component in the coastal zone of the Black Sea. Hydrobiological Journal, 40(5), 62-69.

Grintsov, V. A., \& Poltarukha, O. P. (2004). Functional species groups in the architecture of a fouling community. Oceanology, 44(4), 548-553.

Kaminskaja, L. D., Alekseev, R. P., Ivanova, E. V., \& Sinegub, I. A. (1977). Donnaja fauna pribrezhnoj zony Odesskogo zaliva i prilezhashhih rajonov v uslovijah gidrostroitel'stva [The bottom fauna of the coastal 
zone of the Odessa Bay and the surrounding areas in terms of hydro constructing]. Biology of Sea, 43, 54-64 (in Russian).

Kovaleva, M. A., Boltacheva, N. A., \& Kostenko, N. S. (2012) Mnogoletnjaja dinamika sostojanija poselenij Mytilidae na skalah Karadaga [Long-term dynamics of Mytilidae settlement status on the rocks of Karadag]. Sea Ecological Journal, 11(2), 39-44 (in Russian).

Kovaleva, M. A., Boltacheva, N. A., Makarov, M. V., \& Bondarenko, L. V. (2014). Obrastanija estestvennyh tverdyh substratov (skal) akvatorii Karadagskogo prirodnogo zapovednika [Fouling natural hard substrates (rocks) in waters of Karadag nature reserve]. Ecosystems, Their Optimization and Security, 10, 77-81 (in Russian).

Kukushkin, A. S. (2013). Variability of suspended organic matter in the northwestern Black Sea. Oceanology, 53(5), 554-569.

Losovskaja, G. V. (1977). Ekologija polihet Chernogo morja [Ecology of the Black Sea polychaetes]. Naukova Dumka, Kyiv (in Russian).

Losovskaja, G. V. (1988). Sukcessionnye izmenenija biocenoza midii v severozapadnoj chasti Chernogo morja kak otrazhenie fljuktuacii chislennosti i biomassy rukovodjashhego vida pod vlijaniem zamorov [Successional changes in mussel biocenosis in the north-western part of the Black Sea as a reflection of fluctuations in the number and biomass of the dominant species under suffocation effect]. Ecology of Sea, 28, 33-35 (in Russian).

Losovskaja, G. V., Garkavaja, G. P., \& Salskij, V. A. (1990). Izmenenie donnyh soobshhestv i fluktuacii chislennosti dominirujushhih vidov v uslovijah jevtrofirovanija severo-zapadnoj chasti Chernogo morja [Changes in the benthic communities and population fluctuations of the dominant species in terms of eutrophication of the northwestern part of the Black Sea]. Ecology of Sea, 35, 22-28 (in Russian).

Makarov, Y. N. (2004). Desjatinogie rakoobraznye [Decapod crustaceans]. Naukova Dumka, Kyiv (in Russian).

Makarov, Y. N., \& Varigin, A. Y. (2007). Priznaki vosstanovlenija vidovogo raznoobrazija v Odesskom zalive Chernogo morja [Signs of recovery of species diversity in Odessa Bay of the Black Sea]. Ecological Problems of the Black Sea, 9, 207-210 (in Russian).

Minicheva, G. G. (1996). Reakcii mnogokletochnyh vodoroslej na evtrofirovanie ekosistem [Reactions of multicellular algae to eutrophication of ecosystems] Algology, 6(3), 250-257 (in Russian).

Minicheva, G. G., Tuchkovenko, Y. S., Bolshakov, V. N., Zotov, A. B., \& Rusnak, E. M. (2013). Reakcija al'gosoobshhestv severo-zapadnoj chasti Chemogo morja na lokal'nye, regional'nye i global'nye faktory [Responses of algae communities of the northwestern Black Sea on the impact of local, regional and global factors]. Algology, 23(1), 19-36 (in Russian).

Pesenko, Y. A. (1982). Principy i metody kolichestvennogo analiza v faunisticheskih issledovanijah [Principles and methods for the quantitative analysis of faunal studies]. Nauka, Moscow (in Russian).

Pierri, C., Longo, C., \& Giangrande, A. (2010). Variability of fouling communities in the Mar Piccolo of Taranto (Northern Ionian Sea, Mediterranean Sea). Journal of the Marine Biological Association of the United Kingdom, 90(1), 159-167.

Polonskij, A. B., \& Grintsov, V. A. (2013). Vlijanie shtorma na strukturu zoocenoza, vidovoj sostav i chislennost' bespozvonochnyh u jugozapadnogo poberezh'ja Kryma [The impact of the storm on zoocenosis structure, species composition and abundance of invertebrates in the south-west coast of the Crimea]. Reports of the National Academy of Science of Ukraine, 8, 168-175.

Sara, G., Martire, M., Buffa, G., Mannino, A., \& Badalamenti, F. (2007) The fouling community as an indicator of fish farming impact in Mediterranean. Aquaculture Research, 38, 66-75.

Vorobyova, L. V., \& Sinegub, I. A. (2000). Struktura i kolichestvennye pokazateli zoobentosa obrastanija beregoukrepitel'nyh sooruzhenij u beregov Odessy [Structure and quantitative indicators of zoobenthos fouling in shore protection structures near the coast of Odessa]. Global Positioning System of the Black Sea observations: Fundamental and applied aspects. MGI, Sevastopol (in Russian).

Vorobyova, L. V., Sinegub, I. A., \& Shurova, N. M. (2003). Razvitie issledovanij zoobentosa severo-zapadnoj chasti Chernogo morja za poluvekovoj period (1950-2000) [Development of research on the zoobenthos in the northwestern part of the Black Sea for half a century (1950-2000)]. Ecology Sea, 63, 23-29 (in Russian).

Zaitsev, Y. P. (1992). Ekologicheskoe sostojanie shel'fovoj zony Chernogo morja u poberezh'ja Ukrainy (obzor) [The ecological status of the shelf zone of the Black Sea near the coast of Ukraine (review)]. Hydrobiological Journal, 28(4), 3-18 (in Russian).

Zaitsev, Y. P., \& Jacenko, V. A. (1983). Ekologicheskie aspekty gidrotehnicheskogo stroitel'stva $\mathrm{v}$ pribrezhnoj zone morja [Ecological aspects of hydro technical constructing in the coastal zone of the sea]. Biology of Sea, 5, 6266 (in Russian).

Zaitsev, Y., \& Mamaev, V. (1997). Biological diversity in the Black Sea. A study of change and decline. United Nations Publishers, New York. 